Anderson, Jayne L., Green, A, Yoward, L

$S$ and Hall, $H$ (2016) Criterion Validity of an ankle or waist mounted Actigraph GT3X accelerometer in measurement of body position and step count. In: ER-WCPT Congress (4th European Congress), 11th-12th November 2016, Liverpool. (Unpublished)

Downloaded from: http://ray.yorksj.ac.uk/id/eprint/1849/

Research at York St John (RaY) is an institutional repository. It supports the principles of open access by making the research outputs of the University available in digital form. Copyright of the items stored in RaY reside with the authors and/or other copyright owners. Users may access full text items free of charge, and may download a copy for private study or non-commercial research. For further reuse terms, see licence terms governing individual outputs. Institutional Repository Policy Statement

\title{
RaY
}

Research at the University of York St John

For more information please contact RaY at ray@yorksj.ac.uk 


\section{Rationale and study aims}

D High levels of inactivity are reported for adult hospital ward patients recovering from critical illness. ${ }^{1-2}$

$>$ Immobility in hospital contributes to irreversible functional decline in older populations. ${ }^{3}$

$>$ Conventional methods of activity monitoring (self report, observation) are prone to methodological or operational weaknesses. ${ }^{4}$

$>$ Wearable motion-sensors (accelerometers) offer an objective and unobtrusive alternative to monitoring the type and regularity of activity undertaken by hospitalised patients.

$>$ To be considered a viable alternative, the data they capture must be valid and clinically meaningful.

$>$ This study aimed to investigate if the Actigraph GT3X accelerometer (Figure 1) could identify body position and quantify step count during typical activities undertaken on a hospital ward by simulated patients recovering from critical illness.

\section{Results}

> Fair agreement between waist accelerometer data and video recordings for recognition of lying, sitting and standing postures $(k=0.21: p<0.001)$

$>$ Moderate agreement between ankle accelerometer data and video recordings $(\mathrm{K}=0.43: \mathrm{p}<0.001)$

Ankle accelerometer correctly identified lying position on $91 \%$ of occasions, standing $99 \%$, sitting $32 \%$ )

$>$ Mean differences in step count recorded by the ankle accelerometer compared to observed step count when using a stick or walking frame were smaller than the waist placement (Table 1)

$>$ Figure 2 presents the Bland Altman plot constructed for agreement between step count quantified by the ankle accelerometer and observed step count for the ten metre walk using a stick.

Table 1: Mean differences in step count recorded by accelerometry and direct observation (speed $\geq 0.3 \mathrm{~m} / \mathrm{s}$ ).

\begin{tabular}{l|l|l} 
Walk & $n$ & $\begin{array}{l}\text { Mean difference } \\
\text { type }\end{array}$ \\
& & WA\% limits of agreement - LOA) \\
&
\end{tabular}

ference

$(95 \%$ LOA)

ANKLE PLACEMENT accelerometer

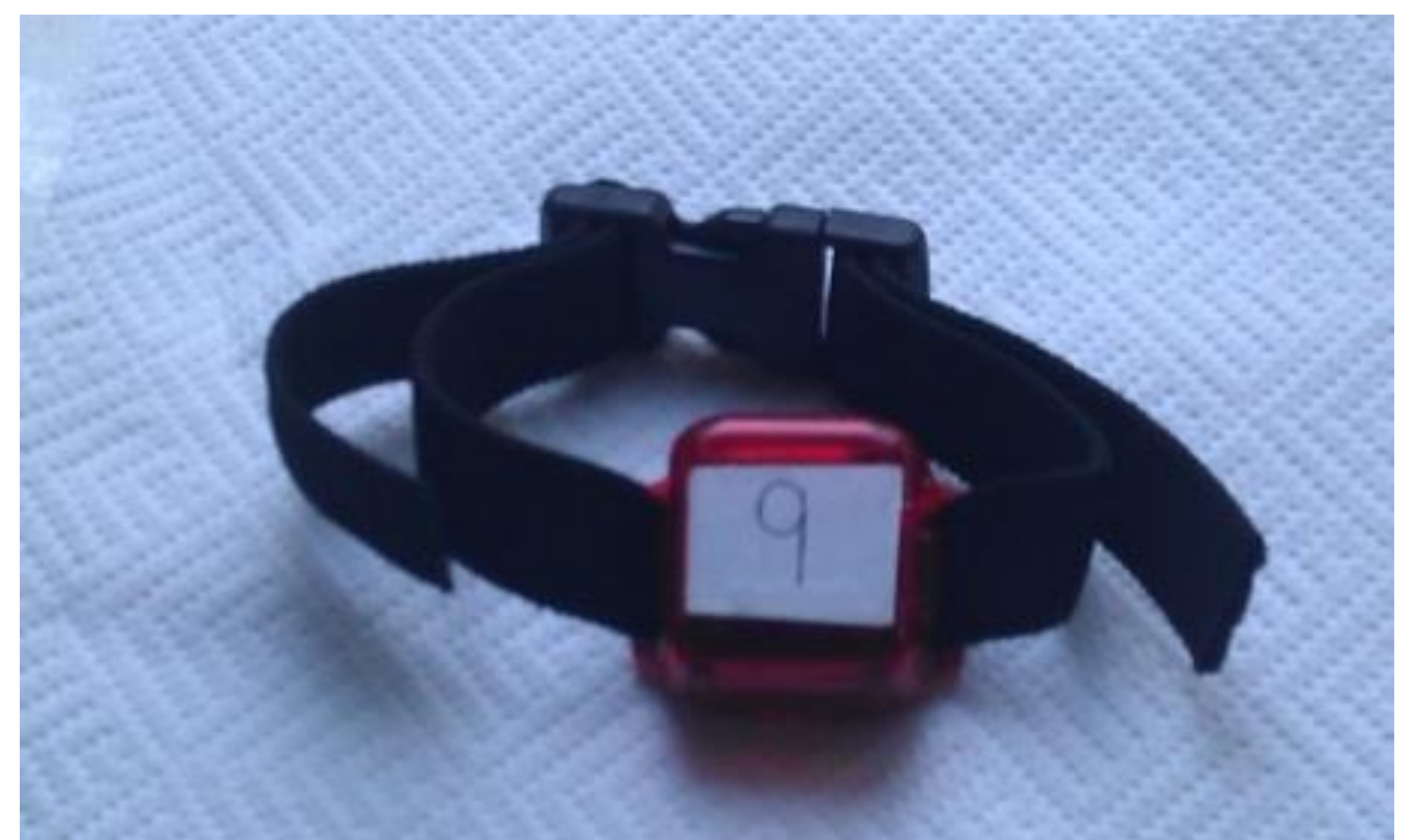

-0.28 steps

(- 5.98 to 5.42 steps)

-0.63 steps

(- 4.69 to 3.43 steps)
Figure 2. Bland Altman plot for ankle accelerometer and stick

\section{Method}

$>$ Observational and prospective in design

$>$ Ethical approval from NHS Research Ethics Committee (14/NI/1023) and York St John University (UC/25/2/14/JA)

$>30$ healthy volunteers enrolled, age matched to a Hull and East Yorkshire Hospitals NHS Trust (HEYHT) critical care population admitted during 2012.

$>$ Research undertaken within a closed hospital ward at HEYHT.

$>$ Participants undertook a movement protocol consisting of postural transitions on a bed (e.g. lying to sitting/ sitting to standing) and ten metre distance walks with walking aids.

$>$ Video recordings formed the criterion measure against which accelerometer data was compared.

$>$ Agreement between accelerometer data and activity observed from the video recordings was analysed using Bland Altman analysis for continuous data

(step count) and Kappa (K) for categorical data (body position).

\section{Conclusions}

$>$ The Actigraph GT3X accelerometer exhibited a delay in recognition of a postural change of $\leq$ nine seconds compared to observation

$>$ Ankle placement was superior to waist placement for identification of body position and step count when undertaking activities typically undertaken by patients recovering from critical illness within a hospital ward environment.

$>$ Whilst the ankle placement accurately identified both lying and standing postures, it often misclassified the sitting position as standing

$>$ Future studies investigating the validity of this model to capture purposeful activity should enrol hospitalised patients recovering from critical illness

$>$ Combinations of accelerometer placement sites may improve identification of the sitting position with this model, using data from multiple placement sites to construct an algorithm.

\section{Acknowledgements}

Special thanks is given to Hull and East Yorkshire Hospitals NHS Trust for their permission to undertake the study within a closed ward and to Dr Victoria Allgar (Hull York Medical School) for statistical advice.

\section{References}

Borges RC., Carvalho CR., Colombo AS., da Silva Borges MP. \& Soriano FG. Physical activity, muscle strength, and exercise capacity 3 months after severe sepsis and septic shock. Intensive Care Medicine. 2015; 41(8):1433-44

Hopkins RO., Miller III RR., Rodriguez, L., Spuhler, V. \& Thomsen, GE. Physical therapy on the wards after early physical activity and mobility in the Intensive Care Unit. Physical Therapy. 2012; 92: 1518-1523. Graf C. Functional decline in hospitalized older adults. The American Journal of Nursing. 2006;106(1):58-67. 